\title{
THE PROTECTIVE EFFECT OF MORINGA TEA AGAINST CYPERMETHRIN-INDUCED HEPATORENAL DYSFUNCTION, OXIDATIVE STRESS, AND HISTOPATHOLOGICAL ALTERATIONS IN FEMALE RATS
}

\author{
SAMEEH A MANSOUR ${ }^{1 *}$, REHAM I MOHAMED ${ }^{1}$, AMINA R ALI ${ }^{1}$, ABDEL-RAZIK H FARRAG ${ }^{2}$ \\ ${ }^{1}$ Environmental Toxicology Research Unit (ETRU), Department of Pesticide Chemistry, National Research Centre, Dokki, Giza, Egypt. \\ ${ }^{2}$ Department of Pathology, National Research Centre, Dokki, Giza, Egypt. Email: samansour@hotmail.com
}

Received: 29 January 2018, Revised and Accepted: 06 June 2018

\section{ABSTRACT}

Objectives: Exposure to $\alpha$-cypermethrin ( $\alpha$-CP) may yield reactive oxygen species (ROS) that is responsible for oxidative stress in mammals. A variety of antioxidants were used to alleviate $\alpha$-CP-induced toxicity in experimental animals. To the best of our knowledge, there are no attempts of using Moringa oleifera $\mathrm{L}$. (MO) plant extracts against $\alpha$-CP-induced toxicity. Therefore, this study was conducted.

Methods: A total of 16 adult female rats were segregated into equally four groups: One group administered $\alpha$-CP orally at a dose of $0.05 / \mathrm{mg} \mathrm{kg} b w /$ day; and the second group was freely allowed to drink MO leaf extract (moringa tea [MOT]) + the $\alpha$-CP dose. The other two groups represented negative and positive controls. The daily consumption of the solutions was estimated. At the end of experiments (28 day), all animals were subjected to the planned manifestations.

Results: MOT has proved its palatability as drinking solution more than water. Compared with control results, the relative weights of liver and brain recorded significant increases, while that of kidney, heart, spleen, ovary, and lung decreased significantly. Furthermore, alterations in the architecture of the liver, kidney, and brain were observed. $\alpha$-CP treatment induced high elevation of the levels of aspartate aminotransferase, alanine amino transferase, alkaline phosphatase, creatinine, and malondialdehyde, while caused decline of butyrylcholinesterase, urea, superoxide dismutase, and total antioxidant capacity levels. Coadministration of MOT restored biochemical and histopathological alterations caused by $\alpha$-CP to a great extent.

Conclusion: The present study introduces novel data on the protective effect of MO leaf extract against CP toxicity and sheds light on the palatability of "MOT" to rodents.

Keywords: Cypermethrin, Oxidative stress, Moringa tea, Amelioration.

(C) 2018 The Authors. Published by Innovare Academic Sciences Pvt Ltd. This is an open access article under the CC BY license (http://creativecommons. org/licenses/by/4. 0/) DOI: http://dx.doi.org/10.22159/ajpcr.2018.v11i10.24993

\section{INTRODUCTION}

Synthetic pyrethroids represent about $30 \%$ of insecticides used globally and are considered the least toxic compared with other classes [1]. They are preferentially used due to their rapid biodegradability and target oriented with respect to their mode of action [2]. Pyrethroids include two types of different chemical structures. Type I includes allethrin, tetramethrin, resmethrin, bioremethrin, and permethrin, while type II includes cypermethrin (CP), cyfluthrin, cyphenothrin, and deltamethrin. Both types inhibit the insect's nervous system [3]. Type I pyrethroids induce hyperexcitation and fine tremors and affect the sodium channels in the closed state [4], while type II causes a more complex syndrome and affects the sodium channels in the open state [5]. In general, the nerve membrane ionic channels represent the primary target of pyrethroid toxicity [6].

The synthetic pyrethroid, $\mathrm{CP}$, is widely used in controlling pests in agriculture, veterinary, and household purposes as a fast-acting neurotoxin to insects [7]. CP technical grade is a racemic mixture of eight isomers (four cis and four trans isomers) and molecular formula of $\mathrm{C}_{22} \mathrm{H}_{19} \mathrm{Cl}_{2} \mathrm{NO}_{3}$. Two stereoisomers, known as $\alpha$-CP, are considered to be the most active forms. $\alpha$-CP is used extensively as an ectoparasiticide in animals, agriculture, and public health programs [8].

Some studies have reported the adverse effects of $\alpha$-CP on brain of laboratory animals $[9,10]$. It causes neurotoxicity in mammals and long-lasting prolongation of sodium permeability during excitation. This may cause severe repetitive nerve impulses in the sense organs and damage to the voltage-dependent sodium channel, causing it to stay open much longer than normal. Therefore, there is a possibility of generating excessive reactive oxygen species (ROS) following exposure to $\mathrm{CP}[11]$.

The insecticide $\alpha$-CP, like other pyrethroids, is metabolized in the liver through hydrolytic ester cleavage and oxidative pathways by cytochrome P-450 enzymes to yield ROS that is responsible for oxidative stress in mammals [12]. Increased ROS levels lead to cytotoxicity and genotoxicity in higher vertebrates $[13,14]$. Moreover, during metabolism of $\alpha$-CP, it forms cyanohydrines and decomposes further to cyanides and aldehydes, substances that can cause production of ROS [15].

Several investigators have used a variety of antioxidantagents to alleviate CP-induced toxicity in experimental animals. For instance, the ethanolic extract of Tribulus terrestris plant was used to alleviate reproductive toxicity of $\alpha$-CP in male Wistar rats [16]. Resveratrol (trans-3,5,4'trihydroxystilbene), a polyphenolic phytoalexin abundantly found in grapes and red wine, was found to ameliorate $\mathrm{CP}$-induced brain damage in Wistar rats [17]. Zinc and $\alpha$-lipoic acid were reported to reduce the harmful effects of $\alpha$-CP on the reproductive system of male rat [18]. To the best of our knowledge, there are no attempts of using the "Miracle Plant, Moringa oleifera L." against $\alpha$-CP toxicity; however, the plant is known for its antioxidant properties [19-23]. For example, MO extracts were reported to ameliorate acetaminophen-induced hepatotoxicity in rats [21]; lead acetate-induced changes in liver and kidney function parameters and oxidative stress markers in rats [22]; diclofenacinduced hepatotoxicity in rats [24]; alcohol-induced hepatotoxicity 
in Wistar rats [25]; cadmium toxicity in rats [26]; and lead toxicity in cerebral cortex in rats [27]. Furthermore, coadministration of MO leaf extract with chlorpyrifos (CPF) caused a significant restoration in brain enzymes and protein as well as restoration of antioxidant capacity. Brain architecture was also well preserved in rats who received CPFMO combination [28]. For the above-mentioned considerations, it may be convenient to present an introductory section on MO.

M. oleifera (Lam.) belonging to the family of Moringaceae is an effective remedy for malnutrition. It is commonly known as "drumstick tree" or "horseradish tree" or the "miracle tree" or "the tree of life." Moringa (MO) is rich in nutrition owing to the presence of a variety of essential phytochemicals present in its leaves, pods, and seeds. Surprisingly, MO is said to provide Vitamins C and A as 7 and 10 times more than oranges and carrots, respectively; 17, 9, 15, and 25 times more calcium, protein, potassium, and iron than milk, yoghurt, bananas, and spinach, respectively [29]. MO is considered as a sustainable remedy for malnutrition in children in countries such as Senegal and Benin [30]. It is used to treat malnutrition in children younger than 3 years. Furthermore, the MO leaf powder (ca. 6 spoonfuls) can meet a woman's daily $\mathrm{Fe}$ and Ca requirements during pregnancy [31]. On the other hand, the aqueous extract of MO leaves was reported to possess antidiabetic activity [32] and the leaf powder has potential antibacterial activity [33].

According to Mishra et al. [34], many companies across the world manufacture various products of MO leaves such as tea, tablets, capsules, soaps, and beverages. Fortunately, boiling of seeds and leaves of MO increased the availability of iron and antioxidant content, and thus soaking the leaves in hot water improves its health effects [35]. Usually, a teaspoon of dried MO leaves (crushed or blended) is added to hot water and allowed to steep for 3-5 min (or until the color changes) to prepare a cup of MOT [34].

The present study was undertaken to provide an overview on the effect of $\alpha$-CP on some physiological, biochemical, and histopathological parameters in female rats and to evaluate the ameliorative effect of MO leaf extract.

\section{METHODS}

\section{Chemicals and reagents}

CP, $\mathrm{C}_{22} \mathrm{H}_{19} \mathrm{Cl}_{2} \mathrm{NO}_{3}$ [cyano-(3-phenoxyphenyl) methyl] 3-(2,2-dichlo roethenyl)-2,2-dimethylcyclopropane-1-carboxylate, was obtained from the Modern Chemical Industries Company, Egypt, in a form of commercial formulation (10\% EC). 2-thiobarbituric acid (2,6-dihydroxypyrimidine-2-thiol) was purchased from Merck (Germany). Dibasic and monobasic sodium phosphates were obtained from Alliance Bio (Irvine, CA, USA). The reagents used in biochemical assay of malondialdehyde (MDA), superoxide dismutase (SOD), transaminases (alanine amino transferase [ALT] and aspartate aminotransferase [AST]), alkaline phosphatase (ALP), total antioxidant capacity (TAC), butyrylcholinesterase (BuChE), urea, and creatinine were purchased from Biodiagnostic Company, Dokki, Giza, Egypt.

\section{Animals}

Healthy female albino rats of the Wistar strain (Rattus norvegicus), 60 days of age, and with average weights of 120-140 g were obtained from the Animal Breeding House of the National Research Centre (NRC), Dokki, Cairo, Egypt, and maintained in clean plastic cages in the laboratory animal room $\left(23^{\circ} \mathrm{C} \pm 2^{\circ} \mathrm{C}\right)$ of $12 / 12 \mathrm{~h}$ daily dark/light cycle. The animals were fed a standard pellet diet and had free access to water for 1 week acclimatization period before experimentation. The experimental work on rats was performed with the approval of the Animal Care and Experimental Committee, NRC, Cairo, Egypt, and in accordance with the guidelines for Care and Use Of Laboratory Animals [36].

\section{Preparation of MOT}

Packets of MO grinded leaves, each of $2 \mathrm{~g}$, were brought from the Unit of Research and Production of Moringa at NRC, Cairo, Egypt. Production of MO products was preceded by voucher specimens deposited in the herbarium of NRC. MOT was prepared by soaking each packet in $300 \mathrm{ml}$ of hot water and kept at room temperature, with occasional swirling, until cooled. The prepared tea extracts were transferred to glass bottles, each contained $300 \mathrm{ml}$, and fixed in the experimental cages (1 bottle/ cage of 4 rats). The bottles were removed every morning, and the daily consumption of MO solution was determined over the experimental duration period (28 days).

\section{Experimental design}

A total of 16 female rats were distributed in four cages, each contained four rats and represented an experimental group (G), as follows: G1: Drinking water only (control group), G2: MOT (300 ml), G3: CP $(0.05 \mathrm{mg} / \mathrm{kg}$ bw/day), and G4: CP (0.05 mg/kg bw/day) + MOT (300 ml). $\mathrm{CP}$ was given orally by gavages at a dose of $0.05 \mathrm{mg} / \mathrm{kg} \mathrm{bw} /$ day which represents its acceptable daily intake (ADI) according to the FAO/ WHO [8]. The insecticide solution was prepared daily in distilled water on active ingredient basis. The concentration of MOT was extrapolated from its traditional use (e.g., a teaspoon of dried MO leaves/cup of hot water) [34]. Both MOT and drinking water were subjected to daily consumption estimation .

\section{Blood and organs' collection}

At the end of the experiment ( 4 weeks), the final body weights were recorded and blood samples were taken from the facial artery of each animal under ether anesthesia and added to non-heparinized centrifuge tubes to separate serum. This was performed by centrifugation at $3500 \mathrm{rpm}(600 \mathrm{~g})$ for $10 \mathrm{~min}$ at $4^{\circ} \mathrm{C}$ using Heraeus Labofuge $400 \mathrm{R}$, Kendro Laboratory Products GmbH, Germany. The sera were kept in a deep freezer $\left(-20^{\circ} \mathrm{C}\right)$ until analyzed. Then, the animals were sacrificed by cervical dislocation, and the heart, spleen, liver, kidneys, lung, brain, and ovaries were removed and weighted. Small pieces of the liver, kidney, and brain were kept in 10\% formalin for histopathological studies. Other pieces of liver $(1 \mathrm{~g}$ tissue $+1 \mathrm{ml}$ phosphate buffer, $\mathrm{pH} 7.4$ ) were homogenized for $1 \mathrm{~min}$ and centrifuged at $4500 \mathrm{rpm}$ for $10 \mathrm{~min}$ at $4^{\circ} \mathrm{C}$. The supernatant was withdrawn in clean tubes and kept in a deep freezer $\left(-20^{\circ} \mathrm{C}\right)$ until analyzed for MDA and SOD.

\section{Biochemical analyses}

The measurements of biochemical parameters were performed on Shimadzu UV-VIS Recording 2401 PC (Japan) Spectrophotometer at the specified wavelengths and in accordance to the pamphlet instructions given by the manufacturers and in the light of the published methods. The activity of AST (EC.2.6.1.1) and ALT (EC.2.6.1.2) was determined according to the method described by Reitman and Frankel [37] at $546 \mathrm{~nm}$, expressing the enzyme's activity in terms of units per liter (U/L). ALP (EC 3.1.1) was measured in sera at $510 \mathrm{~nm}(\mathrm{U} / \mathrm{L})$ according to Belfield and Goldberg [38]. BuChE activity, U/L (BuChE; EC 3.1.1.8), was measured at $405 \mathrm{~nm}$ using the method followed by Knedel and Böttger [39]. Concentration of urea (in milligram per deciliter; $\mathrm{mg} / \mathrm{dl}$ ) was determined in sera at $550 \mathrm{~nm}$ using the method of Fawcett and Scott [40]. Creatinine was measurable at $495 \mathrm{~nm}$ according to Bartels and Bohmer [41] in terms of $\mathrm{mg} / \mathrm{dl}$. Lipid peroxidation (LPO) was determined in terms of MDA which is a marker of LPO according to Satoh [42] at $534 \mathrm{~nm}$, expressing concentration of MDA in terms of $\mathrm{nmol} / \mathrm{g}$ tissue. The SOD (EC1.15.1.1) activity was measured at $560 \mathrm{~nm}$ and expressed in terms of ug/g tissue [43]. The determination of TAC was performed colorimetrically according to Koracevic et al. [44] at $505 \mathrm{~nm}$ in terms of $\mathrm{mM} / \mathrm{L}$.

\section{Histological studies}

Autopsy samples were taken from the liver, kidney, and brain from rats of different groups and fixed in 10\% formalin saline for $24 \mathrm{~h}$. Washing was done in tap water and then dehydrated in ascending grades of alcohol. Specimens were cleared in xylene and embedded in paraffin bees at $56^{\circ} \mathrm{C}$ in a hot air oven for $24 \mathrm{~h}$. Paraffin blocks were prepared for sectioning at $4 \mu$ thickness by slide microtome. The obtained tissue sections were collected on glass slides, deparaffinized, and stained by hematoxylin and eosin stain. Two slides were prepared for each animal; each slide contained two sections for each organ. Ten field areas for 
each section were selected and examined for histopathological changes under light microscope according to Banchroft et al. [45] at $\times 40$. The histopathology was carried out in the Pathology Department, NRC, Cairo, Egypt.

\section{Statistical analysis}

The data were analyzed using GraphPad Prism 5 Demo and expressed as means \pm standard error. Paired samples $(\mathrm{t})$ test was used to compare the data of the control with those of treatments, where $\mathrm{p}<0.05$ and $\mathrm{p}<0.01$ were considered for significant and high significant differences, respectively. p>0.05 meant no significant difference.

\section{RESULTS}

\section{Consumption of MOT}

The average daily consumption of MOT by female rats in MO group (G2; Fig. 1) was found to be 256,271, 277, and $284 \mathrm{ml}$ during the $1^{\text {st }}, 2^{\text {nd }}$, $3^{\text {rd }}$, and $4^{\text {th }}$ week, respectively. This pattern of consumption resembled nearly that obtained for the treatment: CP + MO (G4) and was higher than that obtained for the other two treatments (G1 and G3: water and $\mathrm{CP}$, respectively). In general, the daily use of $300 \mathrm{ml}$ drinking solution for 4 rats was found to be quite enough (Fig. 1)

\section{Body and organs' weights}

The initial body weight was about 140-180 g, and at the end of the experimental period, the body weight in control (G1) and CP + MO (G4) treatments reached $208 \mathrm{~g}$. The other two treatments recorded lower values (Fig. 2).

G1: Control (water); G2: Moringa; G3: Cypermethrin; G4: Cypermethrin + moringa

Table 1 presents the absolute and relative weights of some internal organs. There were no significant differences between results of control (G1) and MO (G2), with respect to absolute and relative weights of the studied organs (e.g., liver, kidney, heart, spleen, ovary, brain, and lung). Compared with control group (G1), the absolute and relative weights of the liver ( $8.73 \mathrm{~g}$ and $4.2 \%)$ recorded significant differences $(\mathrm{p}<0.05)$ than those for the treatment of CP (G3). Either the absolute or relative weights of the kidney in the CP treatment (G3) were significantly $(p<0.01)$ lower than control values. Similar result trend was obtained for the heart, spleen, ovary, and lung. The absolute and relative weights of control brain recorded $1.78 \mathrm{~g}$ and $0.89 \%$, respectively, values which were significantly lower $(\mathrm{p}<0.01)$ than those obtained for the CP treatment (G3). In general, coadministration of MO with CP (G4) narrowed the differences between their results and those of control treatments (Table 1).

\section{Biochemical parameters}

Table 2 shows the results of biochemical parameters in female rats treated with $\mathrm{CP}$, with and without coadministration of MO. Control value for ALT activity recorded $25.01 \mathrm{U} / \mathrm{L}$, a value which was nearly equal to that recorded for MO and CP + MO treatments (25.03 and $26.9 \mathrm{U} / \mathrm{L}$, respectively). CP treatment (G3) showed highly significant elevation $(\mathrm{p}<0.01)$ in ALT activity, accounting to $53.0 \mathrm{U} / \mathrm{L}$. This means that coadministration of MO brought down the activity of ALT to the normal level. Typical pattern was obtained for AST and ALP activities.

CP treatment (G3) caused high significant $(\mathrm{p}<0.01)$ decline in BuChE activity $(2517.1 \mathrm{U} / \mathrm{L})$, compared with that obtained for control treatment (3110.1U/L). Coadministration of MO (G4) resulted in 3090.9 U/L as BuChE activity, revealing insignificant difference than control result.

Urea and creatinine, as kidney function parameters, recorded 40.01 and $0.75 \mathrm{mg} / \mathrm{dl}$, respectively, in G1. Exposure to cypermethrin (G3) induced a high significant decline in urea concentration and high significant elevation in creatinine concentration. Coadministration of MO (G4) normalized urea level $(\mathrm{p}<0.01)$ and improved creatinine level to some extent $(\mathrm{p}<0.05)$
Exposure of female rats to the insecticide $\mathrm{CP}$ induced a high elevation in LPO (represented by MDA), and severe decline in SOD and TAC activities. Coadministration of MO normalized the MDA and SOD levels $(\mathrm{p}<0.01)$ and improved the TAC level to some extent $(\mathrm{p}<0.05)$ (Table 2).

\section{Histopathological studies}

Sections from the liver, kidney, and brain were subjected to histological examination to study the effects of CP treatment on the tissue integrity

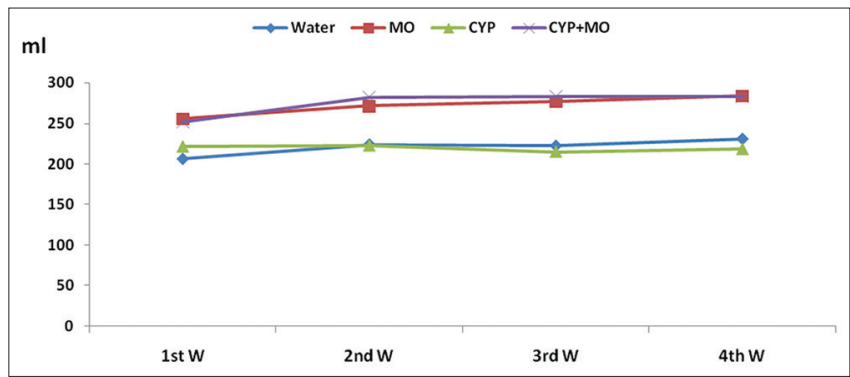

Fig. 1: Average daily consumption of administered solutions to the female rats during the experimental period ( 4 weeks). Experimental groups: G1: Water; G2: Moringa; G3: Cypermethrin; G4: Cypermethrin + moringa

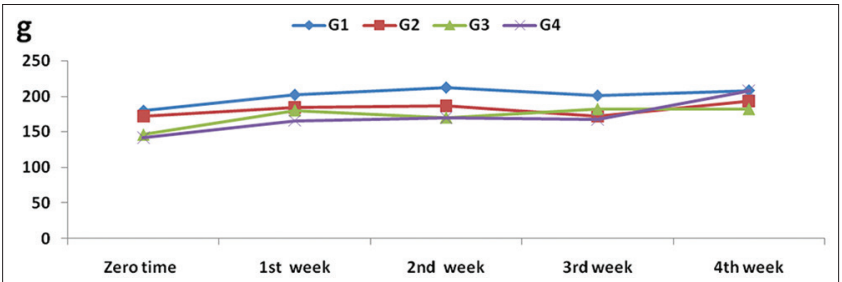

Fig. 2: Fluctuation of body weight of the tested female rats during the experimental period ( 4 weeks)

Table 1: Absolute and relative organs weights of female rats treated with cypermethrin with and without moringa

\begin{tabular}{|c|c|c|c|c|}
\hline \multirow{2}{*}{$\begin{array}{l}\text { Organs } \\
\text { weights }\end{array}$} & \multicolumn{4}{|l|}{ Groups } \\
\hline & G1 & G2 & G3 & G4 \\
\hline \multicolumn{5}{|l|}{ Liver } \\
\hline Absolute (g) & $8.73 \pm 0.49^{\mathrm{a}}$ & $8.58 \pm 0.28^{\mathrm{a}}$ & $7.89 \pm 0.67^{\mathrm{b}}$ & $8.08 \pm 0.47^{\mathrm{a}}$ \\
\hline Relative (\%) & $4.2 \pm 0.01^{\mathrm{a}}$ & $4.4 \pm 0.03^{\mathrm{a}}$ & $4.8 \pm 0.02^{\mathrm{b}}$ & $4.3 \pm 0.005^{\mathrm{a}}$ \\
\hline \multicolumn{5}{|c|}{ Kidney } \\
\hline Absolute (g) & $2.06 \pm 0.21^{\mathrm{a}}$ & $1.77 \pm 0.13^{\mathrm{a}}$ & $1.55 \pm 0.09^{c}$ & $1.75 \pm 0.09^{\mathrm{a}}$ \\
\hline Relative (\%) & $1.41 \pm 0.003^{\mathrm{a}}$ & $1.38 \pm 0.02^{\mathrm{a}}$ & $0.99 \pm 0.001^{\mathrm{c}}$ & $1.21 \pm 0.003^{\mathrm{b}}$ \\
\hline \multicolumn{5}{|c|}{ Heart } \\
\hline Absolute (g) & $0.95 \pm 0.02^{\mathrm{a}}$ & $0.89 \pm 0.04^{\mathrm{a}}$ & $0.73 \pm 0.06^{\mathrm{c}}$ & $0.83 \pm 0.04^{\mathrm{b}}$ \\
\hline Relative (\%) & $0.70 \pm 0.001^{\mathrm{a}}$ & $0.68 \pm 0.2^{\mathrm{a}}$ & $0.59 \pm 0.003^{\mathrm{c}}$ & $0.66 \pm 0.005^{b}$ \\
\hline \multicolumn{5}{|l|}{ Spleen } \\
\hline Absolute (g) & $1.03 \pm 0.06^{\mathrm{a}}$ & $1.11 \pm 0.04^{\mathrm{a}}$ & $0.99 \pm 0.05^{b}$ & $1.0 \pm 0.03^{\mathrm{a}}$ \\
\hline Relative (\%) & $0.47 \pm 0.03^{\mathrm{a}}$ & $0.45 \pm 0.005^{\mathrm{a}}$ & $0.39 \pm 0.01^{\mathrm{c}}$ & $0.41 \pm 0.004^{b}$ \\
\hline \multicolumn{5}{|c|}{ Ovary } \\
\hline Absolute (g) & $0.41 \pm 0.07^{\mathrm{a}}$ & $0.45 \pm 0.05^{\mathrm{a}}$ & $0.26 \pm 0.01^{\mathrm{c}}$ & $0.37 \pm 0.02^{\mathrm{b}}$ \\
\hline Relative (\%) & $2.5 \pm 0.003^{\mathrm{a}}$ & $2.47 \pm 0.001^{\mathrm{a}}$ & $2.12 \pm 0.5^{\mathrm{c}}$ & $2.35 \pm 0.2^{\mathrm{a}}$ \\
\hline \multicolumn{5}{|c|}{ Brain } \\
\hline Absolute (g) & $1.78 \pm 0.003^{\mathrm{a}}$ & $1.81 \pm 0.01^{\mathrm{a}}$ & $2.45 \pm 0.2^{\mathrm{c}}$ & $1.91 \pm 0.001^{b}$ \\
\hline Relative (\%) & $0.89 \pm 0.006^{\mathrm{a}}$ & $0.88 \pm 0.003^{\mathrm{a}}$ & $1.03 \pm 0.02^{\mathrm{c}}$ & $0.91 \pm 0.003^{a}$ \\
\hline \multicolumn{5}{|l|}{ Lung } \\
\hline Absolute (g) & $2.02 \pm 0.03^{\mathrm{a}}$ & $2.12 \pm 0.01^{\mathrm{a}}$ & $1.81 \pm 0.005^{c}$ & $2.08 \pm 0.00$ \\
\hline Relative (\%) & $1.07 \pm 0.05^{\mathrm{a}}$ & $1.1 \pm 0.003^{\mathrm{a}}$ & $0.93 \pm 0.001^{\mathrm{c}}$ & $0.98 \pm 0.003^{a}$ \\
\hline \multicolumn{5}{|c|}{ 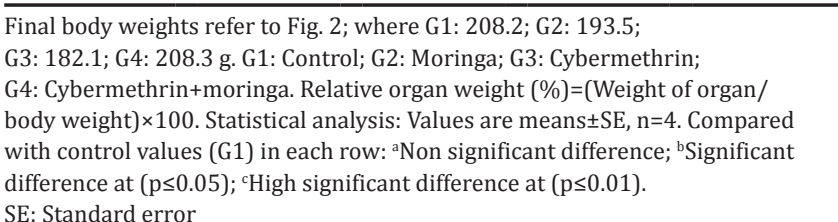 } \\
\hline
\end{tabular}


Table 2: Some biochemical parameters of liver and kidney functions as well as antioxidant enzymes in female rats treated with cypermethrin with and without moringa

\begin{tabular}{|c|c|c|c|c|}
\hline \multirow[t]{2}{*}{ Biochemical markers } & \multicolumn{4}{|l|}{ Groups } \\
\hline & G1 & G2 & G3 & G4 \\
\hline \multicolumn{5}{|l|}{ Liver function enzymes } \\
\hline ALT (U/L) & $25.01 \pm 0.03^{\mathrm{a}}$ & $25.03 \pm 0.01^{\mathrm{a}}$ & $53.0 \pm 0.02^{c}$ & $26.91 \pm 0.2^{\mathrm{a}}$ \\
\hline AST (U/L) & $61.02 \pm 0.01^{\mathrm{a}}$ & $60.09 \pm 0.5^{\mathrm{a}}$ & $70.00 \pm 0.1^{\mathrm{c}}$ & $59.09 \pm 0.04^{a}$ \\
\hline $\operatorname{ALP}(U / L)$ & $90.05 \pm 0.001^{\mathrm{a}}$ & $90.14 \pm 0.2^{\mathrm{a}}$ & $100.1 \pm 0.03^{c}$ & $88.01 \pm 0.01^{\mathrm{a}}$ \\
\hline $\operatorname{BuChE}(\mathrm{U} / \mathrm{L})$ & $3110.1 \pm 0.09^{\mathrm{a}}$ & $3200.3 \pm 0.3^{\mathrm{a}}$ & $2517.1 \pm 0.01^{\mathrm{c}}$ & $3090.9 \pm 0.03^{\mathrm{a}}$ \\
\hline \multicolumn{5}{|c|}{ Kidney function parameters } \\
\hline Urea $(\mathrm{mg} / \mathrm{dl})$ & $40.01 \pm 0.001^{\mathrm{a}}$ & $41.03 \pm 0.03^{\mathrm{a}}$ & $31.52 \pm 0.003^{c}$ & $39.93 \pm 0.4^{\mathrm{a}}$ \\
\hline Creatinine (mg/dl) & $0.75 \pm 0.1^{\mathrm{a}}$ & $0.74 \pm 0.02^{\mathrm{a}}$ & $1.33 \pm 0.05^{c}$ & $0.88 \pm 0.09^{\mathrm{b}}$ \\
\hline \multicolumn{5}{|l|}{ Antioxidant enzymes } \\
\hline MDA (nmol/g tissue) & $4.7 \pm 0.001^{\mathrm{a}}$ & $4.9 \pm 0.5^{\mathrm{a}}$ & $6.1 \pm 0.005^{c}$ & $5.1 \pm 0.03^{\mathrm{a}}$ \\
\hline SOD (ug/g tissue) & $344.0 \pm 0.01^{\mathrm{a}}$ & $341.01 \pm 0.1^{\mathrm{a}}$ & $243.09 \pm 0.03^{c}$ & $339.03 \pm 0.005^{\mathrm{a}}$ \\
\hline $\mathrm{TAC}(\mathrm{mM} / \mathrm{L})$ & $1.66 \pm 0.02^{\mathrm{a}}$ & $1.69 \pm 0.03^{\mathrm{a}}$ & $1.12 \pm 0.09^{c}$ & $1.58 \pm 0.05^{\mathrm{b}}$ \\
\hline
\end{tabular}

G1: Control; G2: Moringa; G3: Cypermethrin; G4: Cypermethrin+moringa. Statistical analysis: Values are means \pm SE, $n=4$. Compared with control values (G1) in each row: ${ }^{a}$ Non-significant difference; bignificant difference at $P \leq 0.05$; ${ }^{c} \mathrm{High}$ significant difference at $\mathrm{P} \leq 0.01$. ALT: Alanine aminotransferase, AST: Aspartate aminotransferase, ALP: Alkaline phosphatase, BuChE: Butyrylcholinesterase, MDA: Malondialdehyde, SOD: Superoxide dismutase, TAC: Total antioxidant capacity, SE: Standard error

Table 3: Assessment of oxidative stress of cypermethrin based on the estimation of percentage of change in some biochemical parameters and ameliorative effect of moringa coadministration

\begin{tabular}{lllll}
\hline Biochemical parameters $^{\dagger}$ & Control value $^{\mathbf{a}}$ & Cypermethrin value $^{\mathbf{b}}$ & \% of change & \\
\hline AST (U/L) & 61.02 & 70.00 & 14.7 & 1.15 \\
ALP (U/L) & 90.05 & 100.1 & 11.2 & 1.11 \\
BuChE (U/L) & 3110.1 & 2517.1 & -19.1 & 0.81 \\
MDA (nmol/g tissue) & 4.7 & 6.1 & 29.8 & 1.30 \\
SOD (ug/g tissue) & 344.0 & 243.09 & -29.3 & 0.71 \\
TAC (Mm/L) & 1.66 & 1.12 & -32.5 & 0.67 \\
\hline
\end{tabular}

${ }^{\dagger}$ Data of biochemical parameters refer to Table 2. c)\% of change=b-a/a×100; d) amelioration index=b/a. AST: Aspartate aminotransferase, ALP: Alkaline phosphatase, BuChE: Butyrylcholinesterase, MDA: Malondialdehyde, SOD: Superoxide dismutase, TAC: Total antioxidant capacity

and to evaluate possible repair following coadministration of MO. Results of this part of study are illustrated in Figs. 3-5.

Microscopic examination of liver sections (Fig. 3) from control (G1) and MO (G2) showed the normal architecture of the hepatic lobule, represented by strongly eosinophilic granulated cytoplasm and round nuclei with peripherally dispersed chromatin and prominent nucleoli. The Kupffer cells are satellite and site on the sinusoidal surface of the endothelial cell, projecting in the vascular space. Sections of the liver of rats given CP (G3) showed hemorrhagic areas in the dilated hepatic sinusoids, and active Kupffer cells were found. Some nuclei showed karyolytic or karyorrhexis feature. The hepatic lobule appeared more or less like normal and active Kupffer cells was seen in the sections of liver from rats given CP + MO (G4) (Fig. 3).

Microscopic examination of kidney sections (Fig. 4) from control (G1) and MO (G2) showed the normal architecture of the two major components of kidney, the renal corpuscle, and the renal tubule. The glomerulus, urinary space, and Bowman's capsule are well seen. Kidney sections from rats treated with CP (G3) showed intraglomerular hemorrhagic areas and degeneration in the renal tubules, as well as cell debris in the lumina of the renal tubules. Kidney sections from rats given MO + CP (G4) showed the renal corpuscles and tubules appeared more or less like normal (Fig. 4).

Microscopic examination of sections in brain cerebrum (Fig. 5) of control rats (G1) showed the highly active neurons that have huge nuclei with relatively pale-stained, the nuclear chromatin, and prominent nucleoli disappeared. The surrounding support cells (glial cells) having small nuclei with densely stained, condensed chromatin with no visible nucleoli and background substance (neuropil). Sections in brain cerebrum of rats given MO (G2) showed the normal structure of the neurons and glial cells. Sections in brain cerebrum of rats administered
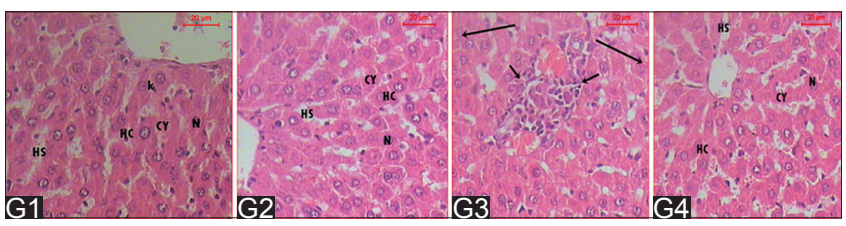

Fig. 3: A micrograph of liver sections from control rats (G1) shows the architecture of the hepatic lobule. The hepatocytes (HC) showed strongly eosinophilic granulated cytoplasm (CY) and round nuclei with peripherally dispersed chromatin and prominent nucleoli (N). Between the strands of $\mathrm{HC}$, the hepatic sinusoids are often seen (HS). The Kupffer cells (K) are satellite and site on the sinusoidal surface of the endothelial cell, projecting in the vascular space (H and E, Scale bar: $20 \mu \mathrm{m}$ ). Liver section from rats given moringa for 28 days (G2) shows the normal architecture of the hepatic lobule $(\mathrm{H}$ and $\mathrm{E}$, Scale bar: $20 \mu \mathrm{m}$ ). Liver sections from rats treated with cypermethrin (G3) show necrotic HC associated with moderate lymphocyte infiltration in the portal and periportal tract (short arrows) with dilated and congested veins. HCs with karyolytic nuclei or karyorrhexis are present (long arrow) (H and E, Scale bar: $20 \mu \mathrm{m})$. G4 represents a micrograph of liver sections from rats treated with cypermethrin and moringa. The hepatic lobule appeared more or less like normal and active Kupffer cells were seen ( $H$ and E, Scale bar: $20 \mu \mathrm{m}$ )

CP (G3) showed the neuron damage, shrinkage, and basophilic neurons with core pyknosis. Sections in the brain cerebrum of rats administered MO + CP (G4) showed neurons and glial cells that appeared more or less like normal (Fig. 5).

The details of histopathological effects are presented below the studied organs (Figs. 3-5). 


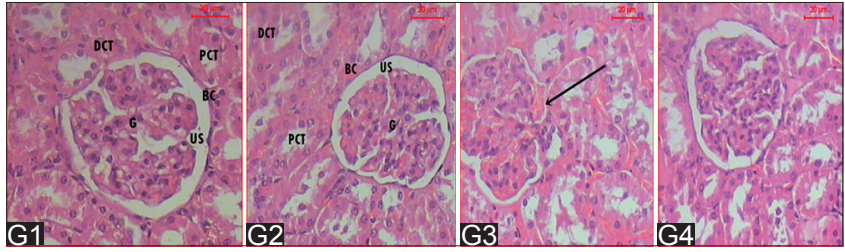

Fig. 4: A micrograph of kidney sections from control rats (G1) shows the renal corpuscle and renal tubules, proximal convoluted tubules (PCT), and distal convoluted tubules (DCT). Notice the glomerulus (G), urinary space (US), and Bowman's capsule (BC) (H and E, Scale bar: $20 \mu \mathrm{m}$ ). Kidney sections from rats given moringa (G2) show the renal corpuscles and tubules appeared more or less like normal (H and E, Scale bar: $20 \mu \mathrm{m}$ ).

Kidney sections from rats treated with cypermethrin (G3) show intraglomerular hemorrhagic areas (long arrow). Notice degeneration in the renal tubules, hemorrhagic areas present in the interstitial spaces, and cell debris in the lumina of the renal tubules ( $\mathrm{H}$ and E, Scale bar: $20 \mu \mathrm{m}$ ). G4 represents a micrograph

of kidney sections from rats treated with cypermethrin and moringa. The renal corpuscles and tubules appeared more or less like normal ( $\mathrm{H}$ and $\mathrm{E}$, Scale bar: $20 \mu \mathrm{m}$ )

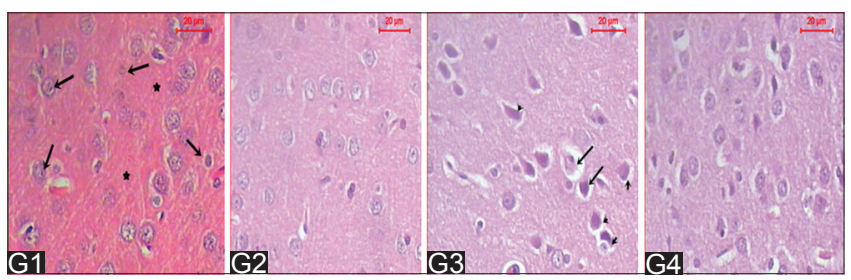

Fig. 5: A micrograph of brain cerebrum sections from control rats (G1) shows the highly active nerve cells (neurons) that have huge nuclei with relatively pale-stained, the nuclear chromatin, and prominent nucleoli disappeared (arrows). The surrounding support cells (glial cells) have small nuclei with densely stained, condensed chromatin with no visible nucleoli (arrow heads), and background substance (neuropil) (star) (H and E, Scale bar: $20 \mu \mathrm{m})$. G2: A micrograph of sections in brain cerebrum of rats given moringa (G2) shows normal structure of the neurons and glial cell (H and E, Scale bar: $20 \mu \mathrm{m})$. Section in brain cerebrum of rats administered cypermethrin (G3) shows cell damage (red arrow), shrinkage of neurons (arrow), and basophilic neurons with core pyknosis (arrow head) (H and E, Scale bar: $20 \mu \mathrm{m}$ ). G4 represents a micrograph of brain cerebrum sections from rats administered cypermethrin and moringa. The neurons and glial cells appeared more or less like normal structure (H and E, Scale bar: $20 \mu \mathrm{m})$

\section{DISCUSSION}

The present study was an attempt to evaluate the toxicity of CP on some physiological, biochemical, and histopathological parameters in female rats and to test the possible ameliorative effect of Moringa olifera leaf extract (MOT) against toxicity of CP. According to the results of the present study, MOT has proved its palatability as drinking solution more than water to the experimental rats.

In toxicological research, the evaluation of organ's toxicity is an important criterion. In general, increase or decrease of body and/ or organs weights than normal could be considered as a preliminary sign of toxicity. Pyrethroid insecticides have poor feed conversion efficiency; therefore, it may affect the body and the organs weights [46]. In this study, except the liver and brain, the relative weights of the other organs (kidney, heart, spleen, ovary, and lung) were decreased significantly as compared with the control treatments. Our results are supported by previous investigations reporting a decline in body and organ weights due to the administration of $\mathrm{CP}$ [47] and the synthetic pyrethroid and deltamethrin in experimental animals [48,49]. In general, coadministration of MO with $\mathrm{CP}$ narrowed the differences between control and CP treatments.

Several studies have reported the alteration of the levels of different biochemical parameters related to liver, kidney, and oxidative status functions in rats following exposure to CP. High elevation of aminotransferases (ALT and AST), ALP, creatinine, and MDA activities and decline of ChE, SOD, and CAT activities than the normal levels were reported by several investigators $[16,17,50,51]$. The results of those investigators support our findings regarding the effect of $\mathrm{CP}$ on the studied biochemical markers.

Activities of the serum enzymes such as AST, ALT, and ALP represent the functional status of the liver, while urea and creatinine levels are indicatives of kidney function. Activities of SOD, TAC, and MDA levels in the liver reflect the oxidative status. Cellular alteration due to exposure to toxicants varies from simple increase of metabolism to the cell death. The increase or decrease of enzyme activity is related to the cellular damage intensity. Therefore, increase of transaminases activity along with the decrease of activity of free radical scavengers may be the consequence of $\alpha$-CP-induced pathological alterations in the liver. The decreased TAC and SOD activities and increased MDA level in the liver as well as increased levels of serum aminotransferases and ALP suggest that $\alpha-\mathrm{CP}$ causes hepatic damage which may be through free radicals formation. $\alpha$-CP undergoes metabolism in the liver through esoteric and oxidative pathways by means of the cytochrome $\mathrm{P}_{450}$ microsomal enzyme system which results in oxidative stress producing decline of TAC and SOD activities and an increase of MDA activity, leading to hepatic necrosis and histopathological damage even at sublethal doses [9,50]. Furthermore, during metabolism of $\alpha$-CP, it forms cyanohydrins which decompose to cyanides and aldehydes, substances that can cause production of ROS [15].

Cholinesterase (ChE), or pseudocholinesterase, is synthesized mainly in hepatocytes and secreted into the bloodstream. In case of liver dysfunction, the ChE activity is declined due to reduced synthesis in contrast to other liver function enzymes whose activities increase due to increased release following damage of cell membrane [52]. Hence, changes in ChE activity reflect alterations in hepatocellular functions and have been recognized as sensitive indicators of the diminished synthetic capacity of the hepatic parenchyma [53]. In the present study, the decline of BuChE activity in CP-treated group corroborated with that recently reported by Mansour et al. [54] in deltamethrin-treated female rats and their pups.

It is documented that the toxicity of various biologically active substances (e.g., pesticides) is associated with the ROS formation which is responsible for inducing oxidative stress in the tissues and chronic permanent damage [55]. Many pesticides may induce oxidative stress following acute exposure in humans [56] and animals [57]. Nevertheless, increased LPO in the tissues may be one of the molecular mechanisms involved in the toxicity of synthetic pyrethroids $[58,59]$.

It has been previously reported that the MO leaves contain different classes of phytochemical compounds, vitamins, and carotenoids. Such these compounds contribute mainly to the antioxidant properties, as well as in other biological activities. $\beta$-carotene from MO leaves is converted efficiently into Vitamin A in the body and has potential hepatoprotective effects [60]. These reported studies have strongly suggested the importance of phenolic compounds from MO and their antioxidant properties. The main antioxidant activity associated with the phenolic contents is their ability to scavenge free radical formation [61]. Such research evidences lead us to suggest that the observed improvement in the biochemical parameters in the CP-treated rats in the present study was attributed to coadministration of the MOT. The scavenging activities of MO can help to modulate the adverse effects of ROS resulted from CP treatment. Extracts of MO leaves were 
extensively reported to possess a wide range of biological activities attributed to the role of MO as antioxidant agent [19-23].

The hepatic and renal function results of the current study corroborated the histopathological lesions observed in the examined organs and supported by the results of Lamfon [62] and Mansour et al. [59] who found that rats treated with deltamethrin have shown loss of normal structure of the hepatic cells, blood congestion, Kupffer cells activation, and hemorrhagic areas and degeneration in the renal tubules. Due to the ability of MO extracts to reduce the oxidative stress induced by toxicants, its high nutritional value could ameliorate and rejuvenate damages in several tissues including liver [63] and cerebral cortex $[27,28]$. Subsequently, this supports the noticeable improvement in the architecture of the studied organs in the present investigation.

It is worthy to mention that Mansour and Gamet-Payrastre [64] have previously reported that alteration in the levels of biochemical parameters due to pesticide exposure is an indicative to how much deviation than normal values due to this pesticide. This could be determined by calculating the percentage of change in pesticidetreated groups relative to untreated control groups. On the other hand, the "amelioration index" (AI) could be estimated by comparing the results of a given biochemical parameter in the groups of pesticides + antioxidant agent (e.g., MO here) with the results of the control groups to assess the ameliorative efficiency of MO. As AI approaches 1, the amelioration reaches a high degree of normalization to the control value [64]. The results of such approach are presented in Table 3 for some biochemical parameters, as examples.

According to the data presented in Table 3, alterations in the activity were differed from a biochemical parameter to another. TAC, SOD, and MDA showed the highest deviation than normal values, accounting to $-32.5 \%,-29.3 \%$, and $29.8 \%$, respectively, due to $\alpha$-CP treatments. Those for AST, ALP, and BuChE were 14.7\%, 11.2\%, and $-19.1 \%$, respectively. These results are comparable with those of Sharma et al. [17] who reported changes accounted to $83.99 \%, 17.08 \%$, and $47.64 \%$ in the activity of MDA, SOD, and AChE, respectively, in male rat brain treated with $\alpha$-CP $(3.38 / \mathrm{mg} \mathrm{kg}$ bw for 28 days); taking into consideration the very high dose used in comparison with our dose $(0.05 / \mathrm{mg} \mathrm{kg}$ bw for 28 days).

On the other hand, the efficiency of MO to alleviate the oxidative stress exerted by exposure to $\alpha-\mathrm{CP}$ has resulted in amelioration indices (AIs) around 1. Values of AI exceeding 1.0 may refer to either better improvement or negligible experimental errors. The obtained results are supported by our previously published investigations on other pesticides and different antioxidants [59,64,65].

\section{CONCLUSION}

The present study explored the role of MO leaf extract to alleviate the oxidative stress exerted by the pyrethroid insecticide, CP, for the first time. This was referred to the scavenging capacity of MO that diminished the hazard effects of ROS exerted by the insecticide, as well as the high nutritional value of MO as a source of powerful antioxidants. Interestingly, the study reveals the palatability of "MOT" to rodents. The study may also encourage further investigations on the pyrethroid insecticides, especially at doses characterized as safe, such as the ADI doses.

\section{CONFLICTS OF INTEREST}

The authors declare that there are no conflicts of interest.

\section{AUTHOR'S CONTRIBUTIONS}

S. A. Mansour: Concept, supervision, critical reviews, and journal submission. R. M. Ibrahim: Materials, animal caring and dosing, literature search, and statistical analysis. A. R. Ali: Animal caring and dosing, literature search, and draft writing. A. H. Farrag: Histological work (anatomy, specimen collections, slide preparation, and reading).

\section{REFERENCES}

1. Shukla Y, Yadav A, Arora A. Carcinogenic and cocarcinogenic potential of cypermethrin on mouse skin. Cancer Lett 2002;182:33-41.

2. Leng $\mathrm{G}$, Kühn $\mathrm{KH}$, Idel $\mathrm{H}$. Biological monitoring of pyrethroid metabolites in urine of pest control operators. Toxicol Lett 1996;88:215-20

3. Wang X, Xue F, Hua A, Ge F. Effects of diapause duration on future reproduction in the cabbage beetle, Colaphellus bowringi: Positive or negative? Physiol Entomol 2006;31:190-6.

4. Verschoyle RD, Aldrige WN. Structure-activity relationship of some pyrethroids in rats. Arch Toxicol 1980;45:325-9.

5. Soderlund DM, Clark JM, Sheets LP, Mullin LS, Piccirillo VJ, Sargent D, et al. Mechanisms of pyrethroid neurotoxicity: Implications for cumulative risk assessment. Toxicology 2002;171:3-59.

6. Narahashi T. Nerve membrane ionic channels as the primary target of pyrethroids. Neurotoxicology 1985;6:3-22.

7. Solati J, Hajikhani R, Zaeim RT. Effects of cypermethrin on sexual behaviour and plasma concentrations of pituitary-gonadal hormones. Int J Fertil Steril 2010;4:23-8.

8. FAO, WHO. Pesticide Residues in Food. Cypermethrin: FAO Plant Production and Protection Paper. Vol 42: FAO, WHO; 1981. p. 79-112.

9. Sayim F, Yavasoglu NU, Uyanikgil Y, Aktug H, Yavasoglu A., Turgut M. Neurotoxic effect of cypermethrin in wistar rats: A haematological, biochemical and histopathological study. J Health Sci 2005;51:300-7.

10. Giray B, Gürbay A, Hincal F. Cypermethrin-induced oxidative stress in rat brain and liver is prevented by vitamin $\mathrm{E}$ or allopurinol. Toxicol Lett 2001;118:139-46.

11. Vijverberg HP, van den Bercken J. Neurotoxicological effects and mode of action of pyrethroid insecticides. Crit Rev Toxicol 1990;21:105-26.

12. Klimek J. Cytochrome P-450 involvement in the NADPH-dependent lipid peroxidation in human placental mitochondria. Biochim Biophys Acta 1990;1044:158-64.

13. Kadous A, Matsumura F, Enan E. High affinity binding of 3- verapamil to rat brain synaptic membrane is antagonized by pyrethroid insecticides. J Environ Sci Health 1994;29:855-71.

14. Kale M, Rathore N, John S, Bhatnagar D. Lipid peroxidative damage on pyrethroid exposure and alterations in antioxidant status in rat erythrocytes: A possible involvement of reactive oxygen species. Toxicol Lett 1999;105:197-205.

15. Wielgomas B, Krechniak J. Effect of $\alpha$-cypermethrin and chlorpyrifos in a 28-day study on free radical parameters and cholinesterase activity in wistar rats. Polish J Environ Stud 2007;16:91-5.

16. Sharma P, Huq AU, Singh R. Cypermethrin induced reproductive toxicity in male wistar rats: Protective role of tribulus terrestris. J Environ Biol 2013;34:857-62.

17. Sharma P, Firdous S, Singh R. Neurotoxic effect of cypermethrin and protective role of resveratrol in wistar rats. Int J Nutr Pharmacol Neuro Dis 1014;4:104-11.

18. Bepari M, Maity P, Das T, Choudhury SM. Zinc and alpha-lipoic acid alleviate cypermethrin induced reproductive toxicity in mature male wistar rat. Int J Life Sci Pharma Res 2014;4:9-20.

19. Lowell JF. The Miracle Tree. Dakar: ACP-EU; 2002. p. 137-9.

20. Sanchez MDI, Lopez CJ, Vazquez NJR. High-performance liquid chromatography method to measure $\alpha$ - and $\beta$-tocopherol in leaves, flowers and fresh beans from Moringa oleifera. J Chromatogr 2006;1105:111-4.

21. Fakurazi S, Sharifudin SA, Arulselvan P. Moringa oleifera hydroethanolic extracts effectively alleviate acetaminophen-induced hepatotoxicity in experimental rats through their antioxidant nature. Molecules 2012;17:8334-50.

22. Onah CE, Meludu SC, Dioka CE, Onuegbu AJ, Onah CF, Ajaghaku DL, et al. Amelioratory effect of Methanolic leaf extract of Moringa oleifera on some liver and kidney function and oxidative stress markers in leadintoxicated rats. Eur J Me Plants 2016;12:1-12.

23. Omodanisi EI, Aboua YG, Oguntibeju OO. Assessment of the antihyperglycaemic, anti-inflammatory and antioxidant activities of the methanol extract of Moringa oleifera in diabetes-induced nephrotoxic male wistar rats. Molecules 2017;22:pii: E439.

24. Hamza AA. Curcuma longa, Glycyrrhiza glabra and Moringa oleifera ameliorate diclofenac induced hepatoxicity in rats. Am J Pharm Toxicol 2007; 2:80-8.

25. Saalu LC, Ogunlade B, Ajayi GO, Oyewopo AO, Akunna GG, Ogunmodede OS. The hepato-protective potentials of Moringa oleifera leaf extract on alcohol-induced hepato-toxicity in wistar rat. Am J Biotechnol Mol Sci 2012;2:6-14.

26. Toppo R, Roy BK, Gora RH, Baxla SL, Kumar P. Hepatoprotective 
activity of Moringa oleifera against cadmium toxicity in rats. Vet World 2015;8:537-40.

27. Owolabi J, William F, Olanrewaju J., Etibor T, Fabiyi O. Histomorphological evidences of Moringa oleifera's ameliorative effects against lead toxicity in cerebral cortex. World J Life Sci Med Res 2014;3:53-8.

28. Oyewole OI, Olabiyi BF. Ameliorating effect of Moringa oleifera leaf extract on chlorpyrifos-induced toxicity in the brain of wistar rats. Am J Biochem 2014;4:93-7.

29. Rockwood JL, Anderson BG, Casamatta DA. Potential uses of Moringa oleifera and an examination of antibiotic efficacy conferred by $\mathrm{M}$. Oleiferaseed and leaf extracts using crude extraction techniques available to under-served indigenous populations. Int J Photother Res 2013;3:61-71.

30. Kasolo JN, Bimenya GS, Ojok L, Ochieng J., Ogwal-okeng JW. Phytochemicals and uses of Moringa oleifera leaves in Ugandan rural communities. J Med Plants Res 2010;4:753-7.

31. Titi T M, Estiasih ES. Effect Lactagogue moringa leaves (Moringa oleifera Lam) powder in rats. J Basic Appl Sci Res 2013;3:430-4.

32. Sugunabai J, Jayaraj M, Karpagam T, Varalakshmi B. Antidiabetic efficiency of Moringa oleifera and Solanum nigrum. Int J Pharm Pharm Sci 2014;6 Suppl. 1:40-2.

33. Singh K, Tafida GM. Antibacterial activity of Moringa oleifera (Lam) leaves against some selected bacteria. Int J Pharm Pharm Sci 2014;6:52-4

34. Mishra SP, Singh P, Singh S. Processing of Moringa oleifera Leaves for human consumption. Bull Env Pharmacol Life Sci 2012;2:28-30.

35. Yang R, Chang L, Hsu J, Wen, BB, Palada C, Chadha ML, et al. Nutritional and functional properties of Moringa leaves from germplasm, to plant, to food, to health. Am Chem Soc 2006;1-17.

36. NRC. Guide for the Care and Use of Laboratory Animals. $8^{\text {th }}$ ed. National Research Council. Washington, DC: The National Academies Press; 2011. p. 157.

37. Reitman S, Frankel S. A colorimetric method for the determination of serum glutamic oxalacetic and glutamic pyruvic transaminases. Am J Clin Pathol 1957;28:56-63.

38. Belfield A, Goldberg DM. Revised assay for serum phenyl phosphatase activity using 4-amino-antipyrine. Enzyme 1971;12:561-73.

39. Knedel M, Böttger R. A kinetic method for determination of the activity of pseudocholinesterase (acylcholine acyl-hydrolase 3.1.1.8.). Klin Wochenschr 1967;45:325-7.

40. Fawcett JK, Scott JE. A rapid and precise method for the determination of urea. J Clin Pathol 1960;13:156-9.

41. Bartels H, Bohmer M. Kinetic determination of creatinine concentration. Clin Chem Acta 1972;37:193-7.

42. Satoh K. Serum lipid peroxide in cerebrovascular disorder determined by a new colorimetric method. Clin Chim Acta 1978;90:37-43.

43. Nishikimi M, Appaji N, Yagi K. The occurrence of superoxide anion in the reaction of reduced phenazine methosulfate and molecular oxygen. Biochem Biophys Res Commun 1972;46:849-54.

44. Koracevic D, Koracevic G, Djordjevic V, Andrejevic S, Cosic V. Method for the measurement of antioxidant activity in human fluids. J Clin Pathol 2001;54:356-61.

45. Banchroft JD, Steven A, Turner DR. Theory and Practice of Histological Techniques. $6^{\text {th }}$ ed. Edinburgh: Churchill Livingstone; 2008.

46. Rajawat NK, Soni I, Mathur P, Gupta G. Cyfluthrin-induced toxicity on testes of Swiss albino mice. Int J Curr Microbiol App Sci 2014;3:334-43.

47. Grewal KK, Sandhu GS, Kaur R, Brar RS, Sandhu HS. Toxic impacts of cypermethrin on behavior and histology of certain tissues of albino rats. Toxicol Int 2010;17:94-8.

48. Bhaumik A, Gupta PK. Teratogenicity of deltamethrin in rats. Ind Vet J 1990;67:213-9.

49. Dubey N, Raina R, Khan AM. Toxic effects of deltamethrin and fluoride on antioxidant parameters in rats. Fluoride 2012;45 3Pt 2:242-6.

50. Manna S, Bhattacharyya D, Basak DK, Mandal TK. Single oral dose toxicity study of $\alpha$-cyperrmethrin in rats 2004 . Ind J Pharmacol 2004;36:25-8.

51. Adjrah Y, Karou SD, Agbonon A, Ameyapoh Y, de Souza C, Gbeassor M. Effect of cypermethrin-treated lettuce (Lactuca sativa) on wistar rat liver. J Appl Pharm Sci 2013;3:128-32.

52. Brown SS, Kalow W, Pilz W, Whittaker M, Woronick CL. The plasma cholinesterases: A new perspective. Adv Clin Chem 1981;221:123-9.

53. Moss DM, Henderson AR. Tietz Textbook of Clinical Enzymology. In: Burtis CA, Ashwood ER, editors. Philadelphia, PA, USA: WB Saunders Co; 1999. p. 617-721.

54. Mansour SA, Mohamed RI, Ali AR. The ameliorative effect of selenium against deltamethrin-induced hepato-renal dysfunction, oxidative stress and histopathological damage in lactating rats and their pups. Curr Top Toxicol 2017;13:57-68.

55. Abdollahi M, Mostafalou S, Pournourmohammadi S, Shadnia S. Oxidative stress and cholinesterase inhibition in saliva and plasma of rats following sub chronic exposure to malathion. Comp Biochem Physiol C Toxicol Pharmacol 2004;137:29-34.

56. Verhagen H, Buijsse B, Jansen E, Bueno-de-Mesquita B. The state of antioxidant affairs. Nutr Today 2006;41:244-50.

57. Mansour SA, Mossa AH. Adverse effects of exposure to low doses of chlorpyrifos in lactating rats. Toxicol Industr Health 2011;27:213-24.

58. Sayeed I, Parvez S, Pandey S, Bin-Hafeez B, Haque R, Raisuddin S, et al. Oxidative stress biomarkers of exposure to deltamethrin in freshwater fish, channa punctatus bloch. Ecotoxicol Environ Saf 2003;56:295-301.

59. Mansour SA, Abbassy MA, Shaldam HA. Zinc ameliorate oxidative stress and hormonal disturbance induced by methomyl, abamectin, and their mixture in male rats. Toxics 2017;5:pii: E37.

60. Dillard CJ, German JB. Phytochemicals: Nutraceuticals and human health 2000. J Sci Food Agric 2000;80:1744-56.

61. Verma AR, Vijayakumar M, Mathela CS, Rao CV. In vitro and in vivo antioxidant properties of different fractions of Moringa oleifera leaves. Food Chem Toxicol 2009; 47:2196-201

62. Lamfon NA. Cinnamon aqueous extract ameliorates deltamethrin induced hepatotoxicity in albino rats. Res J Pharm Biol Chem Sci 2014;5:898-905

63. Ghazal OK, Owolabi JO, William FE, Lambe E. Effects of ethanolic extract of Moringa oleifera leaves 0n lead acetate induced liver damage in adult wistar rats. 2012. Int J Biotech Biomed Res 2012;2:12.

64. Mansour SA, Gamet-Payrastre L. Ameliorative effect of vitamin E to mouse dams and their pups following exposure of mothers to chlorpyrifos during gestation and lactation periods 2016. Toxicol Ind Health 2016;32:1179-96.

65. Mansour SA, Mohamed DA, Gamet-Payrastre L. Indirect exposure of mice pups to endosulfan via their dams during gestation and lactation periods and the ameliorative effect of vitamin E. Hum Exper Toxicol 2014;33:911-27. 